\title{
Monitoramento sanitário de um sistema integrado de tratamento de águas residuárias da suinocultura ${ }^{1}$
}

\author{
Ludmilla S. S. Barros, ${ }^{2}$ Luiz A. do Amaral ${ }^{2}$ e Jorge de L. Júnior ${ }^{3}$
}

RESUMO

Objetivo. Avaliar o potencial de contaminação de águas residuárias da suinocultura.

Métodos. As águas residuárias da suinocultura foram estocadas em um tanque. Depois de 0, 30, 60, 90 e 120 dias de retenção hidráulica, foram incorporadas em lisímetros preenchidos com solos argilosos, arenosos e médios. Esses lisímetros foram então submetidos à simulação de duas condições climáticas: estação de chuvas e estiagem. O número de unidades formadoras de colonias de coliformes totais, coliformes fecais e estreptococos fecais foi medido nos efluentes do tanque de estocagem (para os diversos períodos de retenção hidráulica), nos percolados dos lisímetros e nos três tipos de solo. As análises microbiológicas foram realizadas através da técnica de membrana filtrante. As análises de $\mathrm{pH}$ foram realizadas potenciometricamente.

Resultados. Para os três microrganismos, as reduções bacterianas máximas no tanque de estocagem foram obtidas a partir de 90 dias de retenção. A quantificação bacteriana nos percolados dos três solos foi caracterizada por reduções elevadas. Em relação aos três tipos de solo, os maiores valores de redução bacteriana foram verificados nos solos médios, devido à sua acidez $(p H<7,0)$. Para os coliformes fecais a retenção hidráulica não foi suficiente para permitir a adequação sanitária das águas residuárias e sua utilização na irrigação (valores acima de 1000 UFC.100 mL-1). Nesse caso, a incorporação desses resíduos nos solos foi caracterizada como uma segunda etapa de tratamento.

Conclusões. A retenção da água residuária, seguida da aplicação no solo, mostrou-se eficiente na minimização do efeito contaminante dos resíduos da suinocultura. Recomenda-se uma diminuição no tempo de estocagem das águas residuárias da suinocultura, de 120 para 90 dias.

Palavras-chave

Tratamento da água, poluição da água, contaminação biológica, microbiologia da água.

O presente estudo foi financiado pela Fundação de Amparo à Pesquisa do Estado de São Paulo (FAPESP) e é parte da dissertação de mestrado de Ludmilla S. S. Barros, apresentada ao Curso de Pós-graduação em Saneamento e Qualidade Ambiental da Faculdade de Ciências Agrárias e Veterinárias, Universidade Estadual Paulista (UNESP).

2 UNESP, Faculdade de Ciências Agrárias e Veterinárias, Departamento de Medicina Veterinária Preventiva e Reprodução Animal. Correspondência e pedidos de separatas devem ser encaminhados a Ludmilla S. S. Barros no seguinte endereço: Departamento de Medicina Veterinária Preventiva e Reprodução Animal da Faculdade de Ciências Agrárias e Veterinárias da UNESP, Campus de Jaboticabal, Via de Acesso
$\mathrm{Na}$ suinocultura, os principais métodos de tratamento dos dejetos baseiam-se na coleção e estoque dos resíduos em lagoas anaeróbias ou aeróbias, com subseqüente distribuição em terras destinadas à agricultura (1, 2). A filtração e a ação biológica de

Professor Paulo Donato Castellane, km 5, CEP 14884-9000, Jaboticabal, SP, Brasil. E-mail: ldy@asbyte.com.br/ deora@zipmail.com.br

3 UNESP, Faculdade de Ciências Agrárias e Veterinárias, Departamento de Engenharia Rural. microrganismos, habitualmente presentes nos solos não estéreis, são os principais fatores de remoção microbiológica. A ação biológica é particularmente efetiva nas camadas superficiais do solo, onde a presença do ar facilita os processos aeróbios, mais intensivos do que os anaeróbios, e onde a disponibilidade maior de alimentos possibilita a existência de maior população de microrganismos $(3,4)$. O outro fator determinante para uma eficaz ação 
biológica é o tempo. Com o passar do tempo, ou à medida que diminui a velocidade com que os resíduos percorrem a porção de solo, onde se dá a ação biológica, aumenta a eficiência da remoção $(5,6)$. Por fim, uma retenção microbiana telúrica eficiente é possível quando as seguintes características estão presentes: uma maior quantidade de partículas de argila, uma menor quantidade de água, uma maior capacidade de troca catiônica, uma maior área superficial específica e valores de $\mathrm{pH}$ abaixo de $7,0(5,7)$.

No Brasil, o modelo atual de criação suína, proposto na década de 1970 e baseado em um sistema de integração agricultura-suinocultura, está sendo questionado. Isso ocorre especialmente em regiões como o oeste do Estado de Santa Catarina, onde cerca de $90 \%$ das fontes de abastecimento de água, no meio rural, encontram-se contaminadas por coliformes fecais. Tal situação gera um impasse: de um lado, a suinocultura tem grande importância para a economia do país; de outro, é uma expressiva e potencial fonte de contaminação e poluição dos recursos naturais. Diante do exposto, o objetivo deste projeto foi analisar o potencial de contaminação de águas residuárias da suinocultura no Brasil.

\section{MATERIAIS E MÉTODOS}

\section{Caracterização do sistema integrado de tratamento}

O projeto foi executado em um sistema integrado, constituído por uma caixa de estocagem de água e por 24 lisímetros (figura 1), ambos instalados em área experimental do Departamento de Engenharia Rural da Faculdade de Ciências Agrárias e Veterinárias, Campus de Jaboticabal, Universidade Estadual Paulista (UNESP). O lisímetro é um recipiente representativo do meio ambiente e utilizado para fins de monitoramento em estudos sobre as interações planta-água-solo $(8,9)$.

Cada lisímetro possuía $1 \mathrm{~m}$ de altura, $30 \mathrm{~cm}$ de diâmetro e três anéis fixos em seu interior. A finalidade dos anéis era redirecionar o fluxo de água na sua passagem pela coluna de solo,

FIGURA 1. Visão ampla do local do experimento para avaliar o potencial de contaminação de águas residuárias de suinocultura, enfocando as duas baterias constituídas por 24 lisímetros

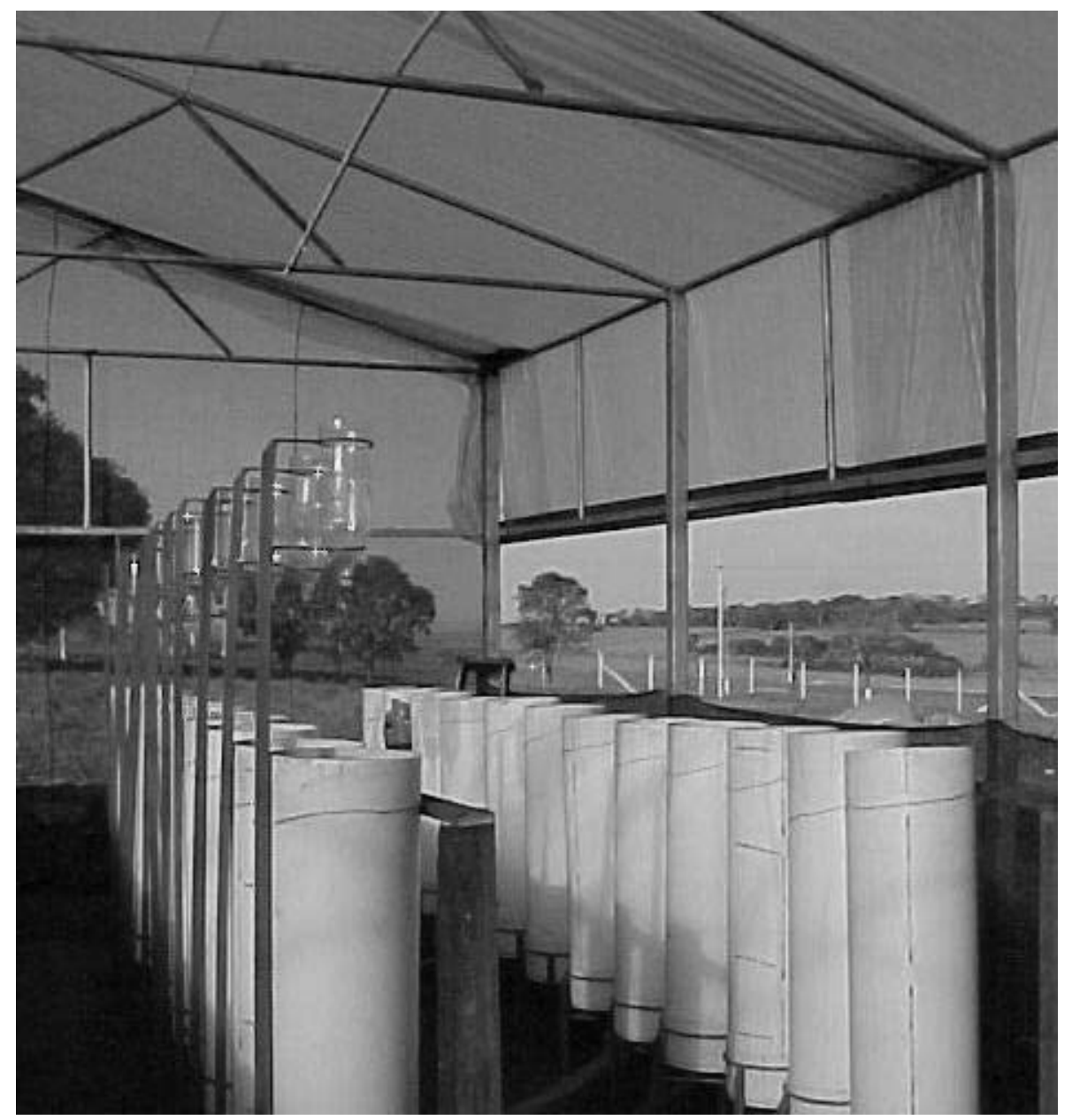

reduzindo assim o efeito parede $(8,9)$. $\mathrm{O}$ efeito parede ocorre quando o solo se separa da parede do lisímetro, criando um espaço de ar. Esses espaços de ar servem como passagens artificiais, permitindo um fluxo rápido de água e o transporte de solutos $(8,9)$. A extremidade posterior dos lisímetros foi selada com um capi, estrutura confeccionada com material tipo PVC, lembrando uma tampa e contendo em seu centro um pequeno orifício, destinado à coleta do material líquido.

Os lisímetros foram preenchidos com três tipos de solo: o arenoso, coletado nas proximidades do Município de Monte Alto (Estado de São Paulo), o argiloso, coletado no Campus Jaboticabal da UNESP, e o médio, coletado na área do aeroporto municipal de Jaboticabal. Após o preenchimento, e antes da incorporação das águas residuárias estocadas no tanque, alíquotas dos três tipos de solo foram enviadas ao Departamento de Solos e Adubos da UNESP para a realização de testes de granulometria composta (análise textural) e de umidade (10).

O pré-tratamento do resíduo foi realizado em um tanque de estocagem, utilizando uma caixa d'água com capacidade de 500 L. Após a determinação dos teores de sólidos totais (11) procurou-se obter um substrato com um teor em torno de $2 \%$ de sólidos totais (12), preparado conforme expressões matemáticas (13). Por fim, para o abastecimento do 
tanque de estocagem, foi determinada uma relação de $38 \mathrm{~kg}$ de esterco para $362 \mathrm{~kg}$ de água.

Após 0, 30, 60, 90 e 120 dias de retenção hidráulica, o resíduo prétratado era incorporado aos lisímetros. Para a determinação da quantidade de resíduo a ser incorporado, primeiramente era quantificado o teor de nitrogênio total no esterco, utilizando o método de nitrogênio total Kjeldahl (14). Em seguida, era realizada a incorporação, tendo como base o teor de nitrogênio total, os valores de nitrogênio indicados para culturas forrageiras (400 kg.ha- $\mathrm{ha}^{-1}$ ano) e a área da superfície de solo do lisímetro $\left(0,068 \mathrm{~m}^{2}\right)$.

Havia, no total, dois conjuntos de lisímetros, cada um com 12 lisímetros. Para a primeira incorporação foi utilizado o primeiro conjunto, sendo seis lisímetros destinados à simulação pluviométrica e seis à estiagem. Para cada situação climática, dois lisímetros eram preenchidos com os solos arenosos, dois com os solos argilosos e dois com os solos médios.

Para a segunda incorporação o segundo conjunto utilizado. Para a terceira incorporação foi utilizado o conjunto da primeira incorporação, uma vez que já haviam transcorrido os 30 dias de simulação pluviométrica e a coleta dos solos. Continuando nessa linha de raciocínio, para a quarta incorporação foi utilizado o segundo conjunto e para a quinta incorporação o primeiro conjunto.

\section{Cálculos da quantidade e da intensidade de aplicação na simulação pluviométrica}

Para a simulação pluviométrica foi realizado um levantamento dos meses críticos de chuva e de estiagem no Município de Jaboticabal entre os anos de 1997 e 1999. Assim, foram identificados os meses de janeiro e agosto de 1999, com 415,9 mm e 0 mm de chuva, respectivamente. A partir dos dados diários da precipitação mensal foram calculados o tempo específico de duração diária $(\Delta t)$ e a quantidade $(\Delta \mathrm{P})$, em $\mathrm{mm}$, da precipitação.

Vale ressaltar que as observações feitas na Estação Agroclimatológica do
Campus de Jaboticabal são cotadas e digitadas em formato padronizado. Após a verificação da consistência dos dados, são efetuados controles de qualidade e obtidas as médias diárias, mensais e anuais, as quais ficam disponíveis para consulta.

Durante a simulação pluviométrica, os percolados dos lisímetros foram coletados em frascos esterilizados de cor âmbar para serem analisados quanto às suas características microbiológicas e químicas. Com a finalização da simulação pluviométrica e da percolação, as amostras dos solos foram coletadas dos lisímetros submetidos aos períodos de chuva e de estiagem, a partir de quatro profundidades: 0 a 5 , 5 a 30, 30 a 60 e 60 a $90 \mathrm{~cm}$. As amostras foram então analisadas quanto às suas características microbiológicas e aos seus valores de $\mathrm{pH}$.

\section{Determinações microbiológicas e químicas}

As diluições decimais das amostras das águas residuárias e dos percolados foram preparadas adicionando-se 10 $\mathrm{mL}$ da amostra a $90 \mathrm{~mL}$ do diluente (água peptonada a 0,1\%), obtendo-se uma diluição de $10^{1}$. A partir dessa diluição foram preparadas, da mesma maneira, as diluições subseqüentes. Para as diluições do solo, $10 \mathrm{~g}$ do solo foram pesados e a esse volume foram adicionados $90 \mathrm{~mL}$ do diluente, obtendo-se uma diluição de $10^{1}$. Após a homogeneização a mistura foi filtrada em gaze esterilizada, a fim de se retirar a parte mais grosseira e, a partir do filtrado, foram realizadas as diluições subseqüentes.

Para a determinação dos coliformes totais, coliformes fecais e estreptococos fecais foi utilizada a técnica de membrana filtrante $(11,15)$. Os resultados das amostras líquidas foram expressos como unidades formadoras de colônias por $100 \mathrm{~mL}$ (UFC.100 $\mathrm{mL}^{-1}$ ), e das amostras sólidas, como unidades formadoras de colônias por grama (UFC.g ${ }^{-1}$ ) (11). O $\mathrm{pH}$ nas amostras líquidas foi determinado utilizando-se o peagômetro DIGIMED modelo DMPH-2. Nas amostras sólidas, a determinação foi potenciométrica, em solução de $\mathrm{CaCl}_{2}$ 0,01 M.

Os resultados de $\mathrm{pH}$ dos solos foram submetidos à análise de variância. A diferença entre as médias aritméticas foi comparada pelo teste de Tukey, ao nível de 5\% de probabilidade (16). A eficiência da remoção microbiana foi avaliada, nas amostras líquidas e sólidas, por análise logarítmica.

\section{RESULTADOS}

\section{Tanque de estocagem}

A água residuária in natura (0 dia de retenção no tanque de estocagem) demonstrou a maior contaminação bacteriana em comparação com a água residuária estocada nos diferentes tempos (tabela 1). O maior decréscimo dos coliformes totais e dos estreptococos fecais (6,33 e 6,30 log, respectivamente) ocorreu nas águas residuárias com 90 dias de retenção hidráulica. Para os coliformes fecais o maior decréscimo $(5,60 \mathrm{log})$ ocorreu

TABELA 1. Contagem de coliformes totais, coliformes fecais e estreptococos fecais em águas residuárias da suinocultura estocadas por diferentes períodos de retenção hidráulica

\begin{tabular}{|c|c|c|c|c|c|c|}
\hline \multirow{2}{*}{$\begin{array}{c}\text { Tempo } \\
\text { de retenção } \\
\text { hidráulica (dias) }\end{array}$} & \multicolumn{2}{|c|}{ Coliformes totais } & \multicolumn{2}{|c|}{ Coliformes fecais } & \multicolumn{2}{|c|}{ Estreptococos fecais } \\
\hline & $\log$ & UFC. $100 \mathrm{~mL}^{-1}$ & $\log$ & UFC. $100 \mathrm{~mL}^{-1}$ & $\log$ & UFC. $100 \mathrm{~mL}^{-1}$ \\
\hline 0 & 13,39 & $2,44 \times 10^{13}$ & 11,90 & $8 \times 10^{11}$ & 11,60 & $4 \times 10^{11}$ \\
\hline 30 & 12,34 & $2,23 \times 10^{12}$ & 10,30 & $2 \times 10^{10}$ & 11,18 & $1,5 \times 10^{11}$ \\
\hline 60 & 9,30 & $20 \times 10^{8}$ & 8,00 & $10 \times 10^{7}$ & 8,00 & $10 \times 10^{7}$ \\
\hline 90 & 7,06 & $115 \times 10^{5}$ & 7,30 & $20 \times 10^{6}$ & 5,30 & $20 \times 10^{4}$ \\
\hline 120 & 8,05 & $113 \times 10^{6}$ & 6,30 & $20 \times 10^{5}$ & 6,41 & $26 \times 10^{5}$ \\
\hline
\end{tabular}


FIGURA 2. Média aritmética de coliformes totais, coliformes fecais e estreptococos fecais nos percolados provenientes dos lisímetros após as incorporações com águas residuárias da suinocultura estocadas por diferentes períodos de retenção hidráulica ${ }^{a}$
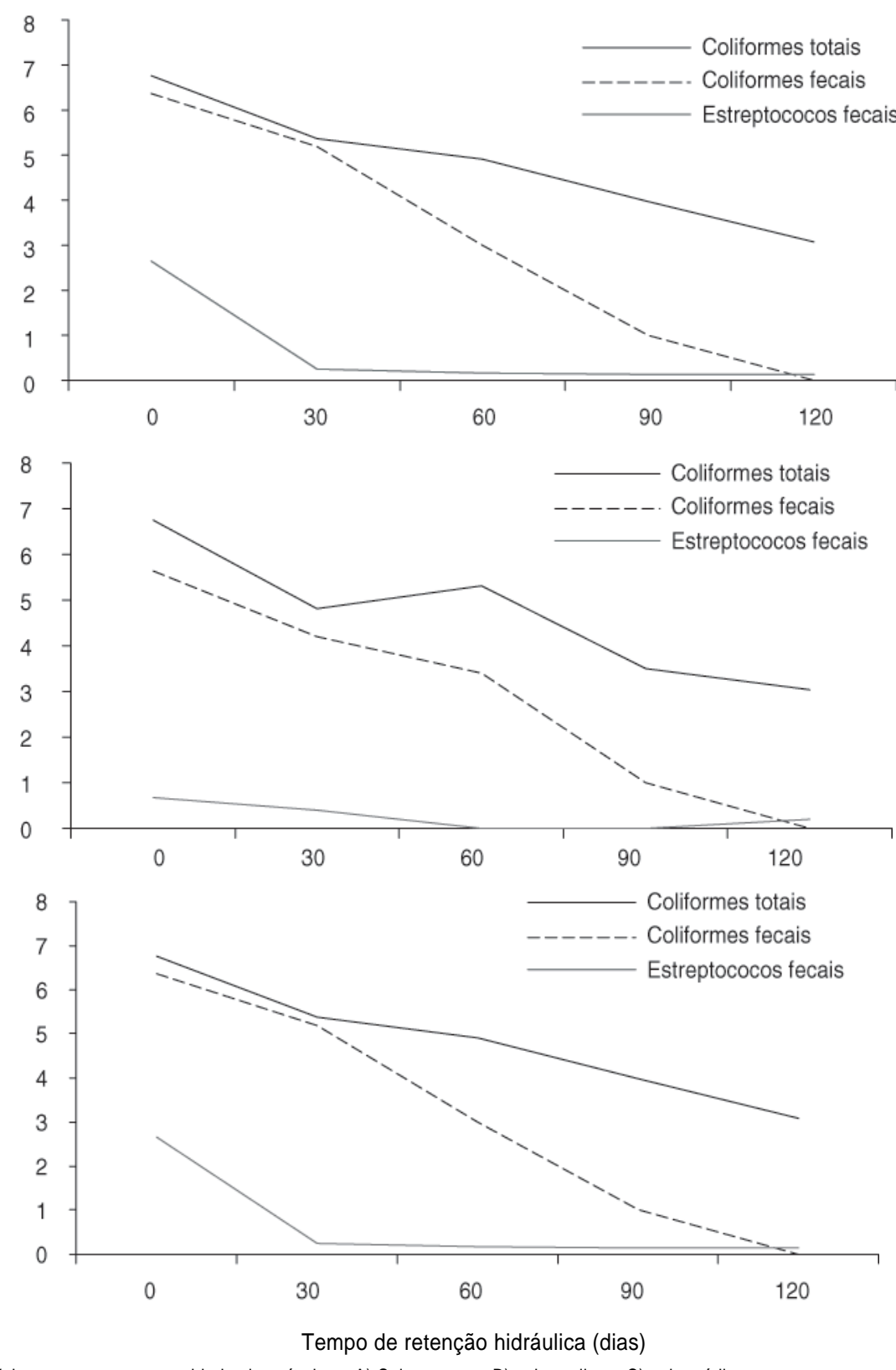

a Valores expressos em unidades logarítmicas. A) Solo arenoso; B) solo argiloso; C) solo médio.

aos 120 dias de retenção hidráulica. Em termos de $\mathrm{pH}$ observaram-se valores crescentes: 6,65 nas águas residuárias in natura; 7,21 após 30 dias; 7,77 após 60 dias; 8,21 após 90 dias; e 8,52 após 120 dias.
B

A

$\log$, respectivamente após a incorporação das águas residuárias com 90 e 120 dias de retenção (tabela 2).

A análise da figura 3 evidencia semelhança quanto ao comportamento dos valores de $\mathrm{pH}$ ao longo do tempo para os três tipos de percolados. Os percolados dos lisímetros preenchidos com os três tipos de solo apresentaram valores de $\mathrm{pH}$ variando entre $7,50 \mathrm{e}$ 8,14, com o ápice ocorrendo nos efluentes com 30 dias de retenção hidráulica. Os percolados provenientes do solo arenoso foram os que apresentaram os maiores valores de $\mathrm{pH}$ durante os 120 dias do experimento.

\section{Solos}

A tabela 3 mostra os resultados relativos às taxas de redução, ao longo do tempo e nas simulações de chuva e estiagem, de coliformes totais, coliformes fecais e estreptococos fecais, para os três tipos de solo.

No solo arenoso, a maior redução dos coliformes totais, na estação das chuvas, foi verificada após a incorporação das águas residuárias in natura. Em contrapartida, a maior redução desse microrganismo indicador na estiagem foi observada após ter sido incorporada a água residuária com 60 dias de retenção hidráulica. Para os coliformes fecais, as maiores taxas de redução, em ambas as condições climáticas, ocorreram após a incorporação das águas residuárias in natura. Para os estreptococos fecais, as maiores taxas de redução foram observadas após a incorporação das águas residuárias com 30 dias de retenção hidráulica, tanto na simulação das chuvas como no período seco.

Nos solos argilosos, a incorporação com as águas residuárias de 60 dias promoveu as maiores taxas de redução dos coliformes totais, tanto na simulação de chuvas quanto de seca. As menores taxas de redução foram observadas após a incorporação das águas residuárias de 120 dias. Todavia, 
TABELA 2. Redução dos coliformes totais, coliformes fecais e estreptococos fecais em percolados oriundos de três tipos de solos após as incorporações com águas residuárias da suinocultura estocadas por diferentes períodos de retenção hidráulica ${ }^{a}$

\begin{tabular}{|c|c|c|c|c|c|c|c|c|c|}
\hline \multirow[b]{2}{*}{$\begin{array}{l}\text { Tempo de retenção } \\
\text { hidráulica (dias) }\end{array}$} & \multicolumn{3}{|c|}{ Percolado do solo arenoso } & \multicolumn{3}{|c|}{ Percolado do solo argiloso } & \multicolumn{3}{|c|}{ Percolado do solo médio } \\
\hline & $\begin{array}{l}\text { Coliformes } \\
\text { totais }\end{array}$ & $\begin{array}{l}\text { Coliformes } \\
\text { fecais }\end{array}$ & $\begin{array}{l}\text { Estreptococos } \\
\text { fecais }\end{array}$ & $\begin{array}{l}\text { Coliformes } \\
\text { totais }\end{array}$ & $\begin{array}{l}\text { Coliformes } \\
\text { fecais }\end{array}$ & $\begin{array}{l}\text { Estreptococos } \\
\text { fecais }\end{array}$ & $\begin{array}{l}\text { Coliformes } \\
\text { totais }\end{array}$ & $\begin{array}{l}\text { Coliformes } \\
\text { fecais }\end{array}$ & $\begin{array}{c}\text { Estreptococos } \\
\text { fecais }\end{array}$ \\
\hline 30 dias & 7,35 & 6,05 & 10,97 & 7,52 & 6,10 & 10,78 & 6,97 & 5,12 & 10,93 \\
\hline 60 dias & 4,29 & 5,17 & 7,64 & 3,99 & 4,60 & 8,00 & 4,40 & 5,00 & 7,83 \\
\hline 90 dias & 3,67 & 6,30 & 5,30 & 3,56 & 6,30 & 5,30 & 3,09 & 6,30 & 5,16 \\
\hline
\end{tabular}

a Valores expressos em unidades logarítmicas.

as maiores taxas de redução para os coliformes fecais foram verificadas após a incorporação da água residuária in natura nas duas simulações, e as menores taxas de redução foram verificadas após a incorporação das águas residuárias de 120 dias, também em ambas as condições climáticas. No que se refere aos estreptococos fecais, as maiores reduções foram verificadas nas chuvas após a incorporação das águas residuárias in natura e com 90 dias, e na seca após terem sido incorporadas as águas in natura e com 120 dias de retenção.

Nos solos médios, a incorporação das águas residuárias com 60 dias resultou nas maiores taxas de redução dos coliformes totais em ambas as situações climáticas, principalmente em comparação com os outros dois tipos de solos. As menores taxas foram verificadas após a incorporação das

FIGURA 3. Valores médios de pH nos percolados provenientes dos lisímetros após as incorporações com águas residuárias da suinocultura estocadas por diferentes períodos de retenção hidráulica

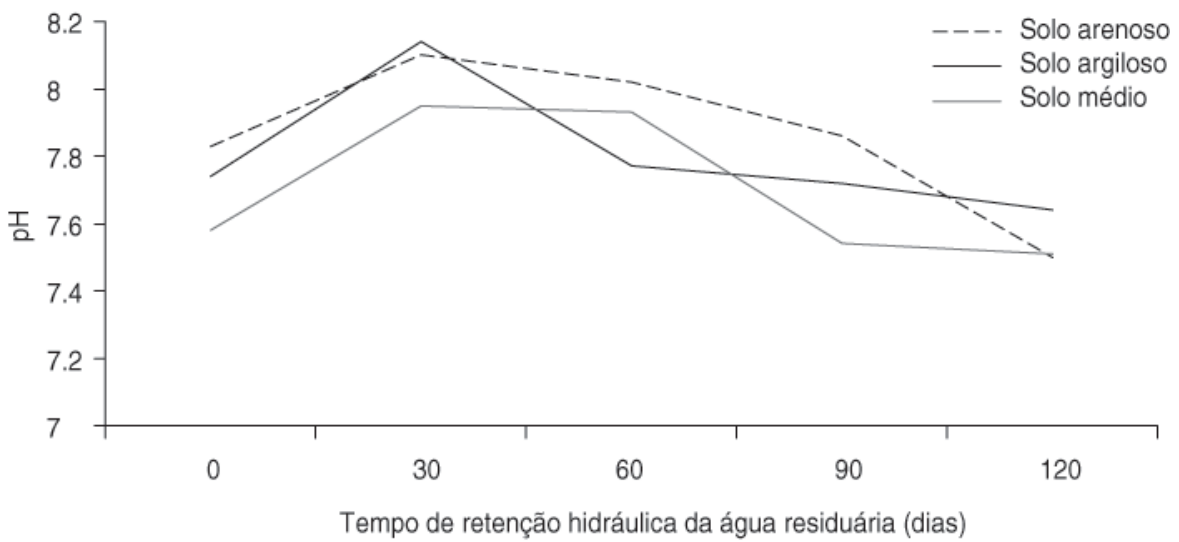

águas residuárias in natura, tanto na situação de chuva quanto na de seca. As maiores taxas de redução para os coliformes fecais, tendo também como parâmetro os outros dois tipos de solos, foram verificadas após a incorporação das águas residuárias de 30 dias e nas duas simulações pluviométricas. As menores taxas de redução estiveram presentes, nas chuvas e na seca, após a incorporação das águas residuárias de 120 dias. Para os estreptococos fecais, as taxas máximas de redução, nas chuvas e na seca, foram verificadas após a incorporação das águas residuárias de 30 dias e das águas residuárias in natura, respectivamente. As taxas mínimas de redução ocorreram após a incorporação das águas residuárias de 60 e 90 dias e nas duas condições meteorológicas.

\section{Granulometria composta e pH}

Os solos argilosos apresentaram a maior capacidade de troca catiônica e os maiores valores de $\mathrm{pH}$ e de umidade (tabela 4). Para os três tipos de solo, os valores médios de $\mathrm{pH}$, nos períodos de chuva e estiagem e nas quatro profundidades analisadas, foram semelhantes nas amostras de solo às quais foram incorporadas a água residuária in natura e nas amostras às quais foram incorporadas as águas submetidas aos quatro tempos de retenção hidráulica (tabelas 5 e 6$)$.

\section{DISCUSSÃO}

As remoções microbiológicas utilizadas neste trabalho foram baseadas na determinação das unidades logarítmicas (UL), a fim de se evitar a superavaliação da remoção dos coliformes (totais e fecais) e dos estreptococos fecais por números tais como 90 e 99,0\% (7, 17). Assim sendo, o pré-tratamento das águas residuárias da suinocultura no tanque de estocagem proporcionou uma eficiência considerável na remoção dos coliformes totais, coliformes fecais e estreptococos fecais, alcançando reduções máximas de 6,33, 5,60 e 6,30 $\log$, respectivamente. Tais achados corroboram estudos anteriores, nos quais foi possível verificar reduções acima de $5 \log$ nos coliformes fecais em efluentes de lagoas anaeróbias abastecidas com águas residuárias da suinocultura $(18,19)$. Os índices máximos de redução para coliformes totais e estreptococos fecais, 
TABELA 3. Redução dos coliformes totais, coliformes fecais e estreptococos fecais em três tipos de solos, sob duas condições climáticas, quatro profundidades e após as incorporações com águas residuárias da suinocultura estocadas por diferentes períodos de retenção hidráulica ${ }^{\mathrm{a}}$

\begin{tabular}{|c|c|c|c|c|c|c|c|c|c|c|c|c|c|c|c|}
\hline \multirow{3}{*}{$\begin{array}{l}\text { Tipo de solo e } \\
\text { profundidade }(\mathrm{cm})\end{array}$} & \multicolumn{15}{|c|}{ Tempo de retenção hidráulica (dias) } \\
\hline & \multicolumn{3}{|c|}{0} & \multicolumn{3}{|c|}{30} & \multicolumn{3}{|c|}{60} & \multicolumn{3}{|c|}{90} & \multicolumn{3}{|c|}{120} \\
\hline & CT & CF & EF & CT & CF & $\mathrm{EF}$ & CT & CF & $\mathrm{EF}$ & CT & CF & $\mathrm{EF}$ & CT & CF & $\mathrm{EF}$ \\
\hline \multirow{2}{*}{\multicolumn{16}{|c|}{$\begin{array}{l}\text { Simulação de chuva } \\
\text { Solo arenoso }\end{array}$}} \\
\hline & & & & & & & & & & & & & & & \\
\hline 0 a 5 & 1,63 & 2,39 & 1,78 & 3,00 & 2,38 & 1,84 & 2,62 & 1,00 & 0,00 & 1,77 & 1,00 & 0,70 & $-0,77$ & $-2,00$ & 1,54 \\
\hline 5 a 30 & 1,13 & 4,17 & 0,74 & 2,74 & 2,01 & 2,55 & 2,81 & 1,00 & $-0,26$ & 1,53 & 1,00 & 0,70 & $-0,60$ & $-2,00$ & 1,92 \\
\hline 30 a 60 & 3,12 & 3,50 & 0,74 & 2,28 & 1,91 & 1,47 & 2,36 & 1,00 & $-1,00$ & 1,62 & 1,00 & 1,30 & $-0,17$ & $-2,00$ & 2,07 \\
\hline $\begin{array}{l}60 \text { a } 90 \\
\text { Solo argiloso }\end{array}$ & 0,88 & 2,40 & 1,00 & 2,74 & 1,14 & 1,74 & 2,20 & 1,00 & $-1,00$ & 1,62 & 1,00 & $-1,00$ & $-1,07$ & $-2,00$ & 1,87 \\
\hline 0 a 5 & 2,47 & 3,73 & 1,90 & 0,49 & 0,70 & $-1,00$ & 2,60 & 1,00 & 0,00 & 2,17 & 1,00 & 0,70 & $-0,77$ & $-2,00$ & 1,39 \\
\hline 5 a 30 & 2,77 & 2,55 & 1,60 & 2,39 & 1,84 & 1,00 & 3,99 & 1,00 & $-1,00$ & 2,17 & 1,00 & 1,30 & $-0,53$ & 2,00 & 1,17 \\
\hline 30 a 60 & 2,40 & 2,77 & 0,00 & 1,53 & 2,13 & 1,39 & 3,14 & 1,00 & $-1,00$ & 2,30 & 1,00 & 1,90 & $-1,07$ & $-2,00$ & 1,77 \\
\hline $\begin{array}{l}60 \text { a } 90 \\
\text { Solo médio }\end{array}$ & 2,33 & 4,00 & 0,00 & 1,61 & 2,13 & 1,00 & 3,47 & 1,00 & $-0,26$ & 2,00 & 1,00 & 1,39 & $-0,68$ & 0,69 & 1,39 \\
\hline 0 a 5 & 2,38 & 1,90 & 1,74 & 3,83 & 3,45 & 2,20 & 4,87 & 1,00 & $-1,00$ & 5,33 & 1,00 & $-1,00$ & 4,34 & $-2,00$ & 0,70 \\
\hline 5 a 30 & 3,92 & 2,06 & 0,00 & 3,47 & 1,00 & 1,17 & 5,51 & 1,00 & $-1,00$ & 5,20 & 1,00 & $-1,00$ & 4,66 & $-2,00$ & $-1,00$ \\
\hline 30 a 60 & 2,70 & 1,84 & 0,00 & 3,47 & 2,87 & 1,00 & 5,53 & 1,00 & $-1,00$ & 4,74 & 1,00 & $-1,00$ & 4,80 & $-2,00$ & 0,70 \\
\hline 60 a 90 & 2,70 & 2,70 & 0,00 & 4,39 & 1,81 & 1,00 & 5,39 & 1,00 & $-1,00$ & 4,90 & 1,00 & $-1,00$ & 4,36 & $-2,00$ & 1,65 \\
\hline \multirow{2}{*}{\multicolumn{16}{|c|}{$\begin{array}{l}\text { Simulação de seca } \\
\text { Solo arenoso }\end{array}$}} \\
\hline & & & & & & & & & & & & & & & \\
\hline 0 a 5 & 0,12 & 2,19 & 1,30 & 2,88 & 1,24 & 3,00 & 2,14 & 1,00 & $-0,26$ & 1,40 & 1,00 & 1,92 & 0,23 & 0,69 & 1,81 \\
\hline 5 a 30 & 1,67 & 2,90 & 1,74 & 3,12 & 2,14 & 1,00 & 2,73 & 1,00 & $-0,26$ & 1,92 & 1,00 & 1,30 & 0,13 & $-2,00$ & 1,74 \\
\hline 30 a 60 & 0,99 & 3,00 & 1,02 & 2,54 & 1,78 & 1,17 & 3,48 & 1,00 & $-1,00$ & 2,07 & 1,00 & 1,00 & $-0,12$ & 1,54 & 1,74 \\
\hline $\begin{array}{l}60 \text { a } 90 \\
\text { Solo argiloso }\end{array}$ & 1,93 & 3,93 & 1,02 & 2,58 & 2,01 & 1,39 & 2,62 & 1,00 & $-1,00$ & 1,62 & 1,00 & 0,70 & 0,04 & $-2,00$ & 1,17 \\
\hline 0 a 5 & 1,20 & 3,02 & 1,95 & 2,70 & 2,59 & 1,00 & 4,74 & 1,00 & $-1,00$ & 3,02 & 1,00 & 1,00 & 0,12 & $-2,00$ & 1,17 \\
\hline 5 a 30 & 2,50 & 4,17 & 2,17 & 2,99 & 3,30 & $-1,00$ & 3,54 & 1,00 & $-1,00$ & 2,69 & 1,00 & $-1,00$ & $-0,77$ & $-2,00$ & 1,00 \\
\hline 30 a 60 & $-0,07$ & 2,00 & 1,02 & 2,14 & 2,74 & $-1,00$ & 5,21 & 1,00 & $-1,00$ & 2,00 & 1,00 & 0,70 & $-0,53$ & $-2,00$ & 1,30 \\
\hline $\begin{array}{l}60 \text { a } 90 \\
\text { Solo médio }\end{array}$ & 2,23 & 3,69 & 1,17 & 2,49 & 2,56 & 1,00 & 5,50 & 1,00 & $-1,00$ & 2,47 & 1,00 & $-1,00$ & 0,31 & $-2,00$ & $-1,00$ \\
\hline 0 a 5 & 1,55 & 1,77 & 1,17 & 3,23 & 2,60 & 1,00 & 4,47 & 1,00 & $-1,00$ & 4,60 & 1,00 & $-1,00$ & 4,41 & $-2,00$ & $-1,00$ \\
\hline 5 a 30 & 3,48 & 1,00 & 0,74 & 3,88 & 3,65 & $-1,00$ & 5,32 & 1,00 & $-1,00$ & 5,37 & 1,00 & $-1,00$ & 5,22 & $-2,00$ & $-1,00$ \\
\hline 30 a 60 & 1,00 & 0,00 & 0,00 & 2,65 & 2,51 & $-1,00$ & 5,96 & 1,00 & $-1,00$ & 5,30 & 1,00 & $-1,00$ & 4,41 & $-2,00$ & $-1,00$ \\
\hline 60 a 90 & 3,17 & 3,00 & 0,00 & 3,60 & 3,41 & $-1,00$ & 5,07 & 1,00 & $-1,00$ & 5,69 & 1,00 & $-1,00$ & 4,64 & $-2,00$ & $-1,00$ \\
\hline
\end{tabular}

a Valores expressos em unidades logarítmicas.

${ }^{\mathrm{b}} \mathrm{CT}=$ coliformes totais; $\mathrm{CF}=$ coliformes fecais; $\mathrm{EF}=$ estreptococos fecais

TABELA 4. Valores de granulometria composta e de umidade dos três tipos de solos antes das incorporações com águas residuárias da suinocultura estocadas por diferentes períodos de retenção hidráulica

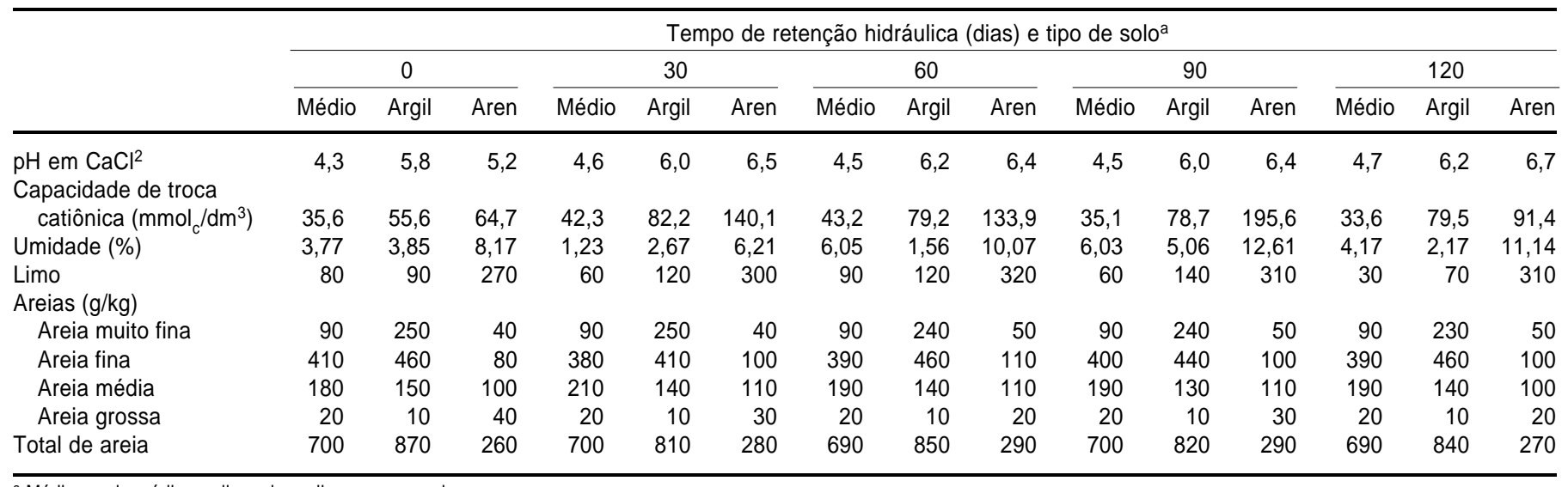

a Médio = solo médio; argil = solo argiloso; aren = solo arenoso. 
TABELA 5. Valores médios de pH nos três tipos de solo após as incorporações com águas residuárias da suinocultura estocadas por diferentes períodos de retenção hidráulica e a simulação das chuvas ${ }^{a}$

\begin{tabular}{|c|c|c|c|c|c|}
\hline \multirow{2}{*}{$\begin{array}{c}\text { Tipo de solo e } \\
\text { profundidade }(\mathrm{cm})\end{array}$} & \multicolumn{5}{|c|}{ pH para diferentes tempos de retenção hidráulica (dias) ${ }^{a}$} \\
\hline & 0 & 30 & 60 & 90 & 120 \\
\hline \multicolumn{6}{|l|}{ Arenoso } \\
\hline 0 a 5 & $5,8^{A}$ & $6,3^{A}$ & $6,7^{\mathrm{A}}$ & $6,3^{A}$ & $6,3^{\mathrm{A}}$ \\
\hline 5 a 30 & $5,9^{A}$ & $6,1^{\mathrm{A}}$ & $6,6^{A}$ & $6,2^{A}$ & $6,3^{\mathrm{A}}$ \\
\hline 30 a 60 & $6^{A}$ & $6,4^{A}$ & $6,8^{\mathrm{A}}$ & $6,4^{A}$ & $6,4^{\mathrm{A}}$ \\
\hline 60 a 90 & $6^{\mathrm{A}}$ & $6,4^{\mathrm{A}}$ & $6,7^{\mathrm{A}}$ & $6,3^{A}$ & $6,4^{A}$ \\
\hline \multicolumn{6}{|l|}{ Argiloso } \\
\hline 0 a 5 & $5,6^{\mathrm{AB}}$ & $7,2^{\mathrm{B}}$ & $7,5^{\mathrm{B}}$ & $7,3^{\mathrm{B}}$ & $7,1^{\mathrm{A}}$ \\
\hline 5 a 30 & $5,4^{A B}$ & $7,2^{\mathrm{B}}$ & $7,5^{\mathrm{B}}$ & $7,3^{\mathrm{B}}$ & $7,1^{\mathrm{A}}$ \\
\hline 30 a 60 & $5,5^{\mathrm{AB}}$ & $7,2^{\mathrm{B}}$ & $7,5^{\mathrm{B}}$ & $7,3^{\mathrm{B}}$ & $7,2^{\mathrm{A}}$ \\
\hline 60 a 90 & $5,5^{\mathrm{A}}$ & $7,2^{\mathrm{B}}$ & $7,5^{\mathrm{B}}$ & $7,2^{\mathrm{B}}$ & $7,2^{\mathrm{A}}$ \\
\hline \multicolumn{6}{|l|}{ Médio } \\
\hline 0 a 5 & $5,2^{\mathrm{AC}}$ & $4,8^{\mathrm{B}}$ & $4,7^{\mathrm{B}}$ & $4,7^{\mathrm{B}}$ & $4,6^{\mathrm{B}}$ \\
\hline 5 a 30 & $4,4^{\mathrm{AC}}$ & $4,7^{\mathrm{B}}$ & $4,7^{\mathrm{B}}$ & $4,6^{\mathrm{B}}$ & $4,6^{\mathrm{B}}$ \\
\hline 30 a 60 & $4,5^{\mathrm{AC}}$ & $4,6^{\mathrm{B}}$ & $4,6^{B}$ & $4,6^{\mathrm{B}}$ & $4,6^{\mathrm{B}}$ \\
\hline 60 a 90 & $4,4^{\mathrm{AC}}$ & $4,6^{\mathrm{B}}$ & $4,6^{\mathrm{B}}$ & $4,6^{\mathrm{B}}$ & $4,6^{\mathrm{B}}$ \\
\hline
\end{tabular}

a Em cada coluna, os valores seguidos de letras maiúsculas diferentes diferem entre si pelo teste de Tukey ao nível de $5 \%$.

TABELA 6. Valores médios de pH nos três tipos de solo após as incorporações com águas residuárias da suinocultura estocadas por diferentes períodos de retenção hidráulica, e a simulação da seca ${ }^{a}$

\begin{tabular}{lccccc}
\hline $\begin{array}{c}\text { Tipo de solo e } \\
\text { profundidade }(\mathrm{cm})\end{array}$ & \multicolumn{5}{c}{ pH para diferentes tempos de retenção hidráulica (dias) } \\
\cline { 2 - 6 } & 0 & 30 & 60 & 90 & 120 \\
\hline Arenoso & & & & & \\
0 a 5 & $6,2^{\mathrm{A}}$ & $6,5^{\mathrm{A}}$ & $6,5^{\mathrm{A}}$ & $6,2^{\mathrm{A}}$ & $6,2^{\mathrm{A}}$ \\
5 a 30 & $5,8^{\mathrm{A}}$ & $6,2^{\mathrm{A}}$ & $6,2^{\mathrm{A}}$ & $6,0^{\mathrm{A}}$ & $6,0^{\mathrm{A}}$ \\
30 a 60 & $5,9^{\mathrm{A}}$ & $6,3^{\mathrm{A}}$ & $6,4^{\mathrm{A}}$ & $6,3^{\mathrm{A}}$ & $6,1^{\mathrm{A}}$ \\
60 a 90 & $5,8^{\mathrm{A}}$ & $6,2^{\mathrm{A}}$ & $6,3^{\mathrm{A}}$ & $6,1^{\mathrm{A}}$ & $6,1^{\mathrm{A}}$ \\
Argiloso & & & & & \\
0 a 5 & $5,9^{\mathrm{A}}$ & $7,3^{\mathrm{B}}$ & $7,3^{\mathrm{B}}$ & $7,3^{\mathrm{A}}$ & $7,1^{\mathrm{A}}$ \\
5 a 30 & $5,6^{\mathrm{A}}$ & $7,2^{\mathrm{B}}$ & $7,3^{\mathrm{B}}$ & $7,2^{\mathrm{A}}$ & $7,0^{\mathrm{A}}$ \\
30 a 60 & $5,6^{\mathrm{A}}$ & $7,3^{\mathrm{B}}$ & $7,2^{\mathrm{B}}$ & $7,4^{\mathrm{A}}$ & $7,2^{\mathrm{A}}$ \\
60 a 90 & $5,5^{\mathrm{A}}$ & $7,2^{\mathrm{B}}$ & $7,2^{\mathrm{B}}$ & $7,2^{\mathrm{A}}$ & $7,1^{\mathrm{A}}$ \\
Médio & & & & & \\
0 a 5 & $5,8^{\mathrm{B}}$ & $4,9^{\mathrm{B}}$ & $5^{\mathrm{AB}}$ & $5,0^{\mathrm{A}}$ & $4,7^{\mathrm{A}}$ \\
5 a 30 & $4,6^{\mathrm{B}}$ & $4,7^{\mathrm{B}}$ & $4,7^{\mathrm{AB}}$ & $4,6^{\mathrm{A}}$ & $4,6^{\mathrm{A}}$ \\
30 a 60 & $4,6^{\mathrm{B}}$ & $4,6^{\mathrm{B}}$ & $4,7^{\mathrm{AB}}$ & $4,6^{\mathrm{A}}$ & $4,6^{\mathrm{A}}$ \\
60 a 90 & $4,5^{\mathrm{B}}$ & $4,7^{\mathrm{B}}$ & $4,7^{\mathrm{AB}}$ & $4,6^{\mathrm{A}}$ & $4,7^{\mathrm{A}}$ \\
\hline
\end{tabular}

a Em cada coluna, os valores seguidos de letras maiúsculas diferentes diferem entre si pelo teste de Tukey ao nível de $5 \%$.

observados a partir das águas residuárias de 90 dias, sugerem uma mudança sanitária no tempo total de estocagem das águas residuárias da suinocultura, passando de 120 (20) para 90 dias.

É possível que as maiores reduções nos coliformes fecais observadas nos dois últimos tempos de retenção hidráulica estejam diretamente relacionadas com os elevados valores de $\mathrm{pH}$, pois, conforme pesquisas anteriores (21-23), à medida que se eleva o $\mathrm{pH}$ se torna evidente a remoção dos coliformes fecais. Porém, mesmo com esses eficientes índices de remoção bacteriana, os coliformes fecais estavam acima de 1000 UFC.100 $\mathrm{mL}^{-1}$ (tabela 1), impedindo a reutilização das águas residuárias na irrigação de culturas perenes e de hortaliças $(24,25)$. Logo, a incorporação desses resíduos no solo foi caracterizada como uma segunda etapa de tratamento, tendo em vista que a simples retenção não foi suficiente para a adequação sanitária dessas águas. Pesquisas anteriores relatam que o número de coliformes fecais e estreptococos fecais presentes nos percolados provenientes da incorporação de efluentes de lagoas de estabilização é influenciado pelos níveis de resíduos aplicados $(26,27)$.

No presente estudo, o alto nível de remoção bacteriana nos percolados reflete a marcante redução da contaminação presente nas águas residuárias do tanque de estocagem. Dentre os três indicadores, os coliformes fecais e os estreptococos fecais apresentaram os maiores índices de remoção, não sendo mais detectáveis nos percolados oriundos das incorporações com as águas residuárias de 90 e 120 dias de retenção hidráulica e, conseqüentemente, não representando riscos potenciais de contaminação à água subterrânea.

De maneira geral, os maiores valores de redução microbiana nos solos foram verificados nas camadas mais permeáveis existentes na superfície dos lisímetros, mesmo dos impermeáveis, demonstrando a eficiência da parte mais superficial do solo na remoção dos microrganismos indicadores de contaminação fecal. Isso explica por que as águas residuárias infiltradas pouco mais de 1 metro no solo superficial, saturado ou não de água, oferecem maior segurança quanto à depuração do que uma percolação de várias dezenas de metros através do lençol freático, onde as condições aeróbias são difíceis $(1,4$, 28).

Taxas de redução ascendentes já nas primeiras camadas dos três tipos de solos podem estar relacionadas com a maior presença de oxigênio nessas camadas, favorecendo, portanto, os processos aeróbios de decomposição da matéria orgânica, mais intensivos do que os anaeróbios $(29,30)$. É importante enfatizar que a capacidade de remoção microbiana do solo é influenciada pela capacidade de troca catiônica, pelo acréscimo de argila e pela quantidade de água, sendo a 
remoção efetivada com a diminuição da parte aquática (5). Logo, elevadas reduções microbianas puderam ser visualizadas, sobretudo na época da estiagem, nos solos argilosos e médios, detentores também dos maiores valores de capacidade de troca catiônica, quando comparados com os solos arenosos.

A característica física e a presença de diferentes sais nos solos determinam o $\mathrm{pH}$, que em solos normais está entre 4 e $7(31,32)$. No presente trabalho, esses valores normais foram encontrados nos solos sem a incorporação das águas residuárias. A incorporação da matéria orgânica no solo favorece a formação de húmus, cuja elevada capacidade de troca catiônica confere uma alta capacidade de tamponamento (17). Essa característica tampão talvez justifique a pouca variação nos valores de $\mathrm{pH}$ observada nos solos submetidos à incorporação das águas residuárias e em seus subseqüentes percolados, quando comparados com os solos sem a matéria orgânica incorporada. Além disso, a ocorrência dos maiores índices de redução bacteriana nos solos médios pode estar conectada com valores de pH abaixo de 7,0, uma vez que, em solos ácidos, as taxas de remoção são mais eficientes $(29,30,32)$.

Com base nos presentes resultados, depreende-se que a primeira fase (estocagem de águas residuárias) proporcionou uma redução bacteriana evidente, porém com valores de coliformes fecais acima do preconizado para a reutilização na irrigação de culturas, sendo necessária uma segunda etapa de tratamento, delineada pela incorporação dos resíduos em solos arenosos, argilosos e médios, seguida de simulações pluviométricas. A incorporação proporcionou percolados seguros do ponto de vista sanitário, com o solo médio sendo o mais indicado para uma eficiente redução microbiológica.

Agradecimentos. Os autores agradecem à Fundação de Amparo à Pesquisa do Estado de São Paulo (FAPESP) pelo apoio financeiro.

\section{REFERÊNCIAS}

1. Dazzo F, Smith P, Hubbell D. The influence of manure slurry irrigation on the survival of fecal organisms in scranton fine sand. J Environ Qual 1973;2:470-473.

2. Nowlin M, Garth B. Manure management no easy solutions: point/counterpoint. J Soil Water Conservation 1997;52(5):314-317.

3. Lance JC, Gerba CP, Melnick JL. Virus movement in soil columns flooded with secondary sewage effluent. Appl Environ Microbiol 1976;32(4):520-526.

4. Nucci NLR, Araújo JLB, Costa e Silva RJ. Tratamento de esgotos municipais por disposição no solo e sua aplicabilidade no estado de São Paulo. São Paulo: Fundação Prefeito Faria Lima - Centro de Estudos e Pesquisas de Administração Municipal; 1978.

5. Reddy KR, Khaleel R, Overcash MR. Behavior and transport of microbial pathogens and indicator organisms in soils treated with organic wastes. J Environ Qual 1981;10(3):255- 266.

6. Thelin R, Gifford GF. Fecal coliform release patterns from fecal material of cattle. J Environ Qual 1983;12(1):57-63.

7. Burge WD, Marsh PB. Infectious disease hazards of landspreading sewage wastes. J Environ Qual 1978;7(1):1-9.

8. Corwin DL. Evaluation of a simple lysimeterdesign modification to minimize sidewall flow. J Contam Hydrol 2000;42(35):35-49.

9. Corwin DL, Lemert RD. Construction and evaluation of an inexpensive weighing lysimeter for studying contaminant transport. J Contam Hydrol 1994;15():107-123.

10. Day PR. Particle fractionation and particle size analysis. Em: Black CA. Methods of soil analysis. Madison: American Society of Agronomy; 1965. Pp. 545-567. (ASA. Agronomy, 9).

11. American Public Health Association. Standard methods for the examination of water and wastewater. 17th ed. Washington: APHA; 1992.

12. Dartora V, Perdomo CC, Tumelero IL. Manejo de dejetos de suínos. Concórdia: EMBRAPA/ CNPSA, EMATER-RS; 1998. (Circular técnica, ano $\left.7, n^{0} 11\right)$.

13. Lucas Júnior, J. Algumas considerações sobre o uso do estrume de suínos como substrato para três sistemas de biodigestores anaeróbios [tese de livre-docência]. Jaboticabal: Faculdade de Ciências Agrárias e Veterinárias, Universidade Estadual Paulista; 1994.

14. Hach Company. DR/2000. Spectrophotometer Handbook. Loveland: Hach Company; 1991.

15. Determinação de coliformes fecais através da técnica de membrana filtrante. São Paulo: Companhia de Tecnologia de Saneamento Ambiental; 1984. (NT. L5. 221).

16. Stell RGD, Torrie JH. Principles and procedures of statistics. New York: McGraw; 1960.

17. Bastos RKX. Utilização agrícola de esgotos sanitários. São Paulo: ABES; 1999.

18. Hill VR, Sobsey MD. Microbial indicator reductions in alternative treatment systems for swine wastewater. Water Sci Technol 1998; 38(12):119-122.

19. Silva SA. Tratamento de esgotos domésticos em lagoas de estabilização em série no nordeste do Brasil. Em: Coleção de trabalhos técnicos resultantes das pesquisas realizadas na EXTRABES 1977-1983. Campina Grande: UFPB/EXTRABES; 1988.

20. Miranda CR. Suinocultura sustentável: a suinocultura no oeste catarinense e o desenvolvimento sustentável. Concórdia: EMBRAPA -CNPSA; 1999. (Circular técnica).

21. Pearson HW, Mara DD, Mills SW, Smallman DJ. Factors determining algal population in waste stabilization ponds and the influence of algae on pond performance. Water $\mathrm{Sci}$ Technol 1987;19(12):131-140.

22. Pearson HW, Mara DD, Mills SW, Smallman DJ. Physicochemical parameters influencing faecal bacterial survival in waste stabilization ponds. Water Sci Technol 1987;19(12):145-152.

23. Pivelli RP. Qualidade das águas. São Paulo: Faculdade de Saúde Pública da USP; 1998.

24. World Health Organization. Health guidelines for the use of wastewater in agriculture and aquaculture. Geneva: WHO; 1989. (Technical Report Series, n. 778).

25. Conselho Nacional do Meio Ambiente. Padrões de qualidade para os parâmetros monitorados na rede de monitoramento, segundo Resolução CONAMA 20/86. 1986. Disponível

em www.cetesb.sp.gov.br/qualidadederios / anexo2. Acessado em 19 julho 2001.

26. Fernández A, Tejedor C, Chordi A. Effect of different factors on the die-off of fecal bacteria in a stabilization pond purification plant. Water Res 1992;26(8):1093-1098.

27. Hedge $P$, Kanwar RS. Impact of manure application on groundwater quality. Em: ASAE Annual International Meeting, 1997, Minnesota. St Joseph: American Society of Agricultural Engineers; 1997.

28. Ibiebele DD, Inyang AD. Environmental movement of indicator bacteria from soil amended with undigested sewage sludge. Environ Pollut 1986;40(1):53-62.

29. Coraucci Filho B, Chernicharo CAL, Andrade Neto CO, Nour EA, Andreoli FN, Souza HN, et al. Bases conceituais da disposição controlada de águas residuárias no solo. Em: Campos JR, Aisse MM, Chernicharo CAL, Van Haandel A, Monteggia LO, Souza Melo $\mathrm{HN}$, et al. Tratamento de esgotos sanitários por processo anaeróbio e disposição 
controlada no solo. Rio de Janeiro: ABES; 1999. Pp. 321-356.

30. Coraucci Filho B, Chernicharo CAL, Andrade Neto CO, Nour EA, Andreoli FN, Souza HN, et al. Tecnologia do tratamento de águas residuárias no solo: infiltração rápida, irrigação e escoamento superficial. Em: Campos JR, Aisse MM, Chernicharo CAL, Van Haandel A, Monteggia LO, Souza Melo
$\mathrm{HN}$, et al. Tratamento de esgotos sanitários por processo anaeróbio e disposição controlada no solo. Rio de Janeiro: ABES; 1999. Pp. 357-408.

31. Brasil. Decreto $\mathrm{n}^{\circ} 8.468$, de 31 de maio de 1976. Aprova o regulamento da Lei no 997 , de 31 de maio de 1976, que dispõe sobre a prevenção e o controle da poluição do meio ambiente. São Paulo: Diário Oficial do Estado; 8 set 1976.
32. Kellner E, Pires EC. Lagoas de estabilização: projeto e operação. Rio de Janeiro: ABES; 1998.

Manuscrito recebido em 19 de julho de 2002. Aceito em versão revisada em 13 de maio de 2003.

ABSTRACT Objective. To assess the potential for contamination of wastewaters from pig farming. Methods. Wastewaters from pig farming were stored in a tank. After 0, 30, 60, 90, and 120 days of hydraulic retention, they were added to lysimeters filled with argillaceous, sandy, or medium soil. Finally, these lysimeters were submitted to simulations of either a rainy season or a dry season. The number of colony-forming units (CFUs) of total coliforms, fecal coliforms, and fecal streptococci was measured in the effluents of the storage tank (for the various periods of hydraulic retention), in the percolate from the lysimeters, and in the three types of soil. The microbiological analyses were carried out using the membrane filter technique. The $\mathrm{pH}$ analyses were done potentiometrically.

Results. For the three microorganisms, the largest decrease in bacterial counts in the storage tanks occurred with 90 or 120 days of retention. There was a marked decrease in the bacterial count in the percolates of the three soils. For the three soil types the greatest reduction in bacterial counts was found in medium soil, due to its acidity ( $\mathrm{pH}<7.0$ ). Hydraulic retention was not sufficient to ensure the sanitary adequacy of the wastewaters and their use for irrigation, given that fecal coliform values were above $1000 \mathrm{CFU}$ per $100 \mathrm{~mL}$. Therefore, adding the residues to the soil was considered a second stage of treatment.

Conclusions. The retention of wastewaters followed by adding them to soil was effective in minimizing the contaminating effect of pig farming residues. The storage time for wastewaters from pig farming could be decreased from 120 to 90 days. 